\title{
Rotundic acid induces Cas3-MCF-7 cell apoptosis through the p53 pathway
}

\author{
MIN-LUN NAN ${ }^{1}$, XUE WANG ${ }^{2}$, HAI-JUN LI ${ }^{3}$, DE-HAI YU ${ }^{4}$, WEN-YI SUN ${ }^{5}$, \\ HONG-MEI XU ${ }^{6}$, YU-FANG HE ${ }^{1,7}$ and QUAN-CHENG ZHAO ${ }^{1}$
}

\author{
${ }^{1}$ Institute of Phytochemistry, Jilin Academy of Chinese Medicine Sciences, Changchun, Jilin 130000; \\ ${ }^{2}$ College of Chinese Medicinal Materials, Jilin Agricultural University, Changchun, Jilin 130042; \\ ${ }^{3}$ Institute of Translational Medicine; ${ }^{4}$ Cancer Center, The First Hospital of Jilin University; ${ }^{5}$ Department of \\ Clinical Pharmacy and Pharmaceutical Management, School of Pharmaceutical Sciences in Jilin University; \\ ${ }^{6}$ Department of Obstetrics, The First Hospital of Jilin University, Changchun, Jilin 130021; ${ }^{7}$ Department of Pharmacy \\ Administration, Changchun University of Chinese Medicine College of Management, Changchun, Jilin 130117, P.R. China
}

Received January 16, 2018; Accepted April 13, 2018

DOI: $10.3892 / \mathrm{ol} .2018 .9616$

\begin{abstract}
In the present study, the functions and mechanisms of rotundic acid (RA) underlying its induction of apoptosis in caspase-3-transfected MCF-7 human breast cancer cells (Cas3-MCF-7 cells) were investigated. RA induced apoptosis in Cas3-MCF-7 cells more efficiently compared with that in MCF-7 cells transfected with control plasmid. The results from an MTT assay demonstrated that RA effectively inhibited Cas3-MCF-7 cell viability in a dose-dependent manner and induced cell apoptosis via caspase- 3 activity within 12 to $48 \mathrm{~h}$. Western blotting and fluorescence-activated cell sorting demonstrated that RA initiated Cas3-MCF-7 cell apoptosis via p53 activation. The silencing of the p53 gene in the Cas3-MCF-7 cell line led to decreased RA-induced Cas3-MCF-7 cell caspase-3 activity and cell apoptosis. Collectively, the results of the present study indicate that caspase-3 serves a critical function in rotundic acid-induced apoptosis, and suggest that caspase-3 deficiency may contribute to the chemotherapy-resistance of breast cancer. Reconstitution of caspase-3 sensitizes MCF-7 breast cancer cells to chemotherapy. RA has the potential for development as a novel drug combined with reconstitution of caspase- 3 gene therapy for the treatment of human breast cancer with caspase-3 deficiency.
\end{abstract}

\section{Introduction}

Breast cancer is a malignant cancer that has the highest cancer-associated morbidity rate worldwide, with an

Correspondence to: Professor Yu-Fang He, Department of Pharmacy Administration, Changchun University of Chinese Medicine College of Management, 2052 Boshuo Street, Changchun, Jilin 130117, P.R. China

E-mail: heyf1974@163.com

Key words: rotundic acid, apoptosis, p53, MCF-7 cells increasing age of onset (1). Each year, 1.2 million women are diagnosed with breast cancer globally, among which the majority succumb at 40-45 years of age (2). Over $33 \%$ of patients with breast cancer eventually succumb to the disease according to epidemiological investigation at 2013 (3). The association between the abnormity of cancer suppressor genes, particularly tumor protein p53, which acts independently, and breast cancer occurrence and progression, has become the focus of an increasing number of studies (4-6). Therefore, by investigating the p53 pathway, novel therapeutic methods, or antitumor discoveries for breast cancer, may be identified.

As chemotherapy and/or radiotherapy are associated with side effects, and because of high mortality rates, patients with cancer often use alternative therapies, including natural or herbal medicines (7). This has resulted in increased interest in and an active search for novel anticancer agents from natural products (8). In traditional Chinese medicine (TCM), medicinal plants and their extracts are used to treat various diseases. Accumulative data concerning TCM have shown marked activity with regard to the effects on the tumor cell death pathway, which can guide tumor treatment decisions and clinical management (9). Currently, compounds with unique chemical entities that are derivatives of natural medicines are a considerable resource for the development of novel medicines (10). Rotundic acid (RA; Fig. 1) is a member of the pentacyclic triterpenoid family and is principally located in Ilex rotunda, Ilex purpurea, Ilex integra and other Aquifoliaceae plants, which can be located throughout China (11). RA can also be isolated from Mussaenda pubescens and Guettarda platypoda of the Rubiaceae family $(12,13)$. Olea europaea and Planchonella duclitan, which are members of the Oleaceae and Sapotaceae families, respectively, also contain RA $(14,15)$.

The anticancer activity of the majority of currently used clinical cytotoxic therapies, including radiotherapy, for patients with cancer, is based on the ability of these therapies to induce cell death programs, such as apoptosis (16-18). As an evolutionarily conserved process, apoptosis is characterized by a number of morphological and biochemical changes, including 
cell shrinkage, nuclear DNA fragmentation and membrane blebbing (19). p53 is an important cancer suppressor gene in tumors. Upon DNA damage or activation of other stress signals, p53 is activated and a range of biological responses occurs, leading to cell cycle arrest, DNA repair and apoptosis in order to prevent the occurrence and progression of tumors (20). Furthermore, Xu et al (21) demonstrated that RA, as one of a number of isolated compounds, exhibited anticancer activity. Lee et al (15) also reported that RA exhibited cytotoxicity, with a half-maximal inhibitory concentration $\left(\mathrm{IC}_{50}\right)$ value of $9.5 \mu \mathrm{M}$ when applied to the MCF-7 cell line; however, its exact mechanism of action has not been completely elucidated. The aim of the present study was to investigate the anticancer effect of RA on the cell growth and apoptosis of human breast cancer cells, and to evaluate whether RA may be a potential antitumor drug for the treatment of the disease.

\section{Materials and methods}

Reagents. RA was isolated and purified from I. rotunda, as reported in our previous study (22). The purity was $\geq 98 \%$ [(as determined by a high-performance liquid chromatography assay in our previous study (22)] and the extraction productivity of RA was much higher than previous methods, up to $100 \mathrm{mg} / \mathrm{g}$. MTT and RNase were purchased from Sigma-Aldrich; Merck KGaA (Darmstadt, Germany). Propidium iodide and the Annexin V-Fluorescein Isothiocyanate (FITC) Apoptosis Detection kit were purchased from BD Biosciences (Franklin Lakes, NJ, USA). Caspase-3 plasmid and the p53 small interfering RNA (siRNA) reagent kit were purchased from Cell Signaling Technology, Inc (catalog no. 6231, Danvers, MA, USA). Dulbecco's modified Eagle's medium (DMEM), trypsin, fetal bovine serum (FBS), PBS, penicillin and streptomycin were obtained from Gibco; Thermo Fisher Scientific, Inc. (Waltham, MA, USA).

Preparation of RA. RA was dissolved in PBS (pH, 7.2) to prepare a stock solution at a concentration of $1.0 \mathrm{mM}$, which was stored at $-20^{\circ} \mathrm{C}$. Complete DMEM [DMEM supplemented with $10 \%$ fetal bovine serum (FBS) and $1 \%$ aforementioned antibiotics] was added to dilute the RA to the appropriate concentrations prior to use.

MCF-7 cell culture and treatment. For transient transfection assays, the MCF-7 cells (American Type Culture Collection, Manassas, VA, USA) at $80 \%$ confluence were transfected with the caspase-3 expression plasmid (with pcDNA as control plasmid, $2.0 \mu \mathrm{g} /$ well, DsRed2,BioVector NTCC Inc. Beijing China) using Lipofectamine ${ }^{\circledR}$ PLUS reagent (Thermo Fisher Scientific, Inc.) according to the manufacturer's protocol. Cells were harvested for RNA extraction at $48 \mathrm{~h}$ and protein extraction at $72 \mathrm{~h}$ following transfection. The cells with optimal overexpression of caspase-3 (Cas3-MCF-7 cells) were confirmed by western blotting and subsequently used for further experiments. MCF-7 cells or Cas3-MCF-7 cells were routinely cultured in complete DMEM, which contained $50 \mathrm{U} / \mathrm{ml}$ antibiotics (penicillin-streptomycin) and 10\% FBS, under the conditions of $5 \% \mathrm{CO}_{2}$ at $37^{\circ} \mathrm{C}$ in a cell incubator (HERAcell 150i; Thermo Fisher Scientific, Inc.). Following trypsinization by $3 \mathrm{ml}$ trypsin for $3 \mathrm{~min}$ and terminate digestion with $3 \mathrm{ml}$ complete DMEM medium, to passage the cells in a 75T flask for 3-5 days, the cells were counted and planted in a 96-well plate in complete DMEM with or without RA for the MTT array or apoptosis detection. All experiments were performed three times and examined at 12, 24 and $48 \mathrm{~h}$.

Effect of RA on Cas3-MCF-7 and control MCF-7 cell viability. The effects of RA on the viability of MCF-7 cells treated with control plasmid and Cas3-MCF-7 cells were detected using MTT assays. Cells were seeded in 96-well plates at a density of $1.0 \times 10^{4}$ cells $/ \mathrm{ml}$ at a volume of $200 \mu \mathrm{l} /$ well. All groups without or with RA $(0,2.0,5.0$ and $12.5 \mu \mathrm{M})$ were incubated at $37^{\circ} \mathrm{C}$ for 12 , 24 and $48 \mathrm{~h}$. MTT $(1.0 \mathrm{mg} / \mathrm{ml})$ was added to each well, and the cells were incubated at $37^{\circ} \mathrm{C}$ for $4 \mathrm{~h}$. The solution was then aspirated, and $100 \mu \mathrm{l}$ dimethylsulfoxide was added. The absorbance at $540 \mathrm{~nm}$ of the 96 -well plates was determined using a microplate spectrophotometer (Synergy H1, BioTek Instruments, Inc., Winooski, VT, USA). The inhibition percentage was calculated as follows: Inhibition percentage $=(1$-the value in experimental group/the value in the control group) $\mathrm{x} 100$.

Flow cytometry analysis of Cas3-MCF-7 cell apoptosis. Annexin V-FITC and PI double-staining flow cytometry analyses were performed. The Cas3-MCF-7 cells were plated in 96-well plates containing $200 \mu \mathrm{l}$ complete DMEM at a density of $5 \times 10^{4}$ cells/well. The induction of apoptosis in the Cas3-MCF-7 cells was examined with or without RA $(2.0,5.0$ and $12.5 \mu \mathrm{M})$. Cas3-MCF-7 cells in centrifuge tubes were then resuspended in a binding buffer. Next, $5 \mu \mathrm{l}$ annexin V-FITC was added to the tubes, which were incubated at $4^{\circ} \mathrm{C}$ for $10 \mathrm{~min}$, followed by the addition of $5 \mu \mathrm{l}$ PI. The samples were then incubated for another $15 \mathrm{~min}$ and immediately analyzed using a flow cytometer (FACScan; BD Biosciences) with FlowJo 7.6 FACS analysis software (FlowJo LLC, Ashland, OR, USA). The cells in the different portions represented the different cell states as follows: The late-apoptotic cells were present in the upper right portion, the viable cells were present in the lower left portion and the early-apoptotic cells were present in the lower right portion.

Reverse transcription-quantitative polymerase chain reaction $(R T-q P C R)$ analysis. Total RNA was isolated from the Cas3-MCF-7 cells using a RNeasy kit (Qiagen, Inc., Valencia, CA, USA), $5 \mu \mathrm{g}$ of each sample was reverse-transcribed using the M-MLV first-stand synthesis system (Invitrogen; Thermo Fisher Scientific, Inc., cDNAs were analyzed in triplicate with the MJ Real-Time PCR System (Bio-Rad Laboratories, Inc., Hercules, CA, USA) according to the manufacturer's protocol. The primers for $\mathrm{p} 53$ and GAPDH were designed and synthesized by Shanghai Sangon Biological Engineering Co. Ltd. (Shanghai, China). The primer sequences for p53 were as follows: Sense, 5'-TTCCCACTGAGGAGTCCAAC-3'; and antisense, 5'-TTG TTCCCGAAACGCTGAG-3'. The GAPDH primers were as follows: Sense, 5'-CCAGGTGGTCTCCTCTGACTT-3' and antisense, 5'-GTTGCTGTAGCCAAATTCGTTGT-3'. Amplification was performed for 40 cycles with a denaturation temperature of $94^{\circ} \mathrm{C}$, annealing temperature of $58^{\circ} \mathrm{C}$ and extension temperature of $74^{\circ} \mathrm{C}$ in a thermal cycler (Veriti; Thermo Fisher Scientific, Inc.). The PCR products were $200 \mathrm{bp}$ in length. RT-qPCR was performed using the Power SYBR Green Master Mix (Takara Bio, Inc., Otsu, Japan) and an ABI 7300 real-time 
PCR detection system (Applied Biosystems, Thermo Fisher Scientific, Inc.). All primers were synthesized by Invitrogen (Thermo Fisher Scientific, Inc.). Fold changes in expression of each gene were calculated by a comparative threshold cycle $(\mathrm{Ct})$ method using the formula $2^{-\Delta \Delta \mathrm{Cq}}(23)$.

Western blotting. Cas3-MCF-7 cell lysates were extracted using radioimmunoprecipitation buffer (Beyotime Institute of Biotechnology, Shanghai, China) supplemented with a cocktail protease inhibitor (Roche Molecular Diagnostics, Pleasanton, CA, USA), and the protein concentration was determined using a BCA protein assay kit (Beyotime Institute of Biotechnology) according to the manufacturer's protocol. A total of 5-40 $\mu \mathrm{g}$ cell total protein was separated by $10 \%$ SDS-PAGE. The proteins were then transferred onto polyvinylidene difluoride membranes (GE Healthcare, Chicago, IL, USA) by electroblotting. The membranes were blocked at $37^{\circ} \mathrm{C}$ for $1 \mathrm{~h}$ with $5 \%$ skim milk in Tris-buffered saline (TBS) with Tween-20 (0.1\%) and then incubated with the anti-caspase-3 (cat no. 9662; 1:1,000), anti-cleaved caspase-3 (cat no. 9661; 1:1,000), anti-p53 (cat no. $9282 ; 1: 1,000$ ) and anti- $\beta$-actin (cat no. $4967 ; 1: 1,000$ ) antibodies for $1.5 \mathrm{~h}$ at room temperature. The membranes were then washed with Tris-buffered saline washing buffer six times for $5 \mathrm{~min}$ each at room temperature and incubated with horseradish peroxidase-conjugated goat anti-mouse (cat no. TA130001) or goat anti-rabbit (cat no. TA130015) second antibodies (1:2,000; OriGene Technologies, Inc., Beijing, China) at $37^{\circ} \mathrm{C}$ for $1 \mathrm{~h}$. Following washing by TBS buffer, protein bands were visualized using an enhanced chemiluminescence system (Thermo Fisher Scientific, Inc.). The primary antibodies used were all obtained from Cell Signaling Technology Inc. Protein expression levels were determined semi-quantitatively by densitometric analysis with the Quantity One software (V4.62, Bio-Rad Laboratories, Inc., Hercules, CA, USA).

Statistical analysis. All data and results were calculated from at least three replicate measurements and are presented as the mean \pm standard deviation. The significance between the experimental groups and the control group were determined using a two-way analysis of variance (ANOVA) followed by a Dunnett's t-test using SPSS version 20.0 (IBM Corp., Armonk, NY, USA). $\mathrm{P}<0.05$ was considered to indicate a statistically significant difference.

\section{Results}

Effect of RA on MCF-7 and Cas3-MCF-7 cell viability. The effect of RA on the viability of MCF-7 cells was detected using an MTT assay. The structure of RA is illustrated in Fig. 1. The MTT assay revealed that RA had limited function with regard to the viability of the MCF-7 cells treated with control plasmid, as illustrated in Fig. 2A. This phenomenon may be due to the lack of caspase- 3 in the MCF-7 cells. Therefore, caspase-3 was transfected into MCF-7 cells (Cas3-MCF-7 cells) for subsequent experiments. The inhibitory effects of $\mathrm{RA}$ on the Cas3-MCF-7 cells were dose-dependent within the range of 2-12.5 $\mu \mathrm{mol} / 1$ (Fig. 2B). Treatment with RA at $12.5 \mu \mathrm{mol} / 1$ elicited the greatest inhibitory effect, with a cell viability at $32.3 \%$, compared with that of the blank control group $(\mathrm{P}<0.001)$. There were no differences in inhibition

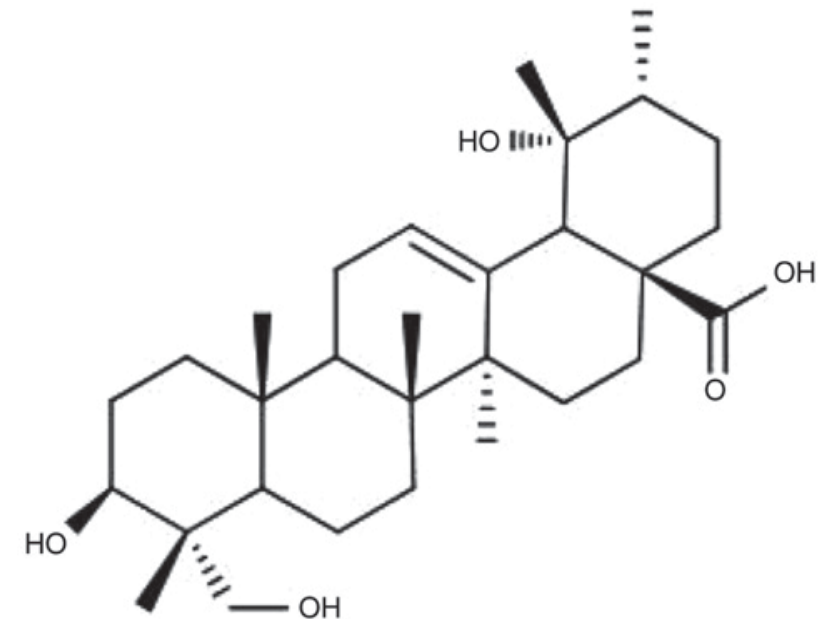

Figure 1. Structure of rotundic acid.
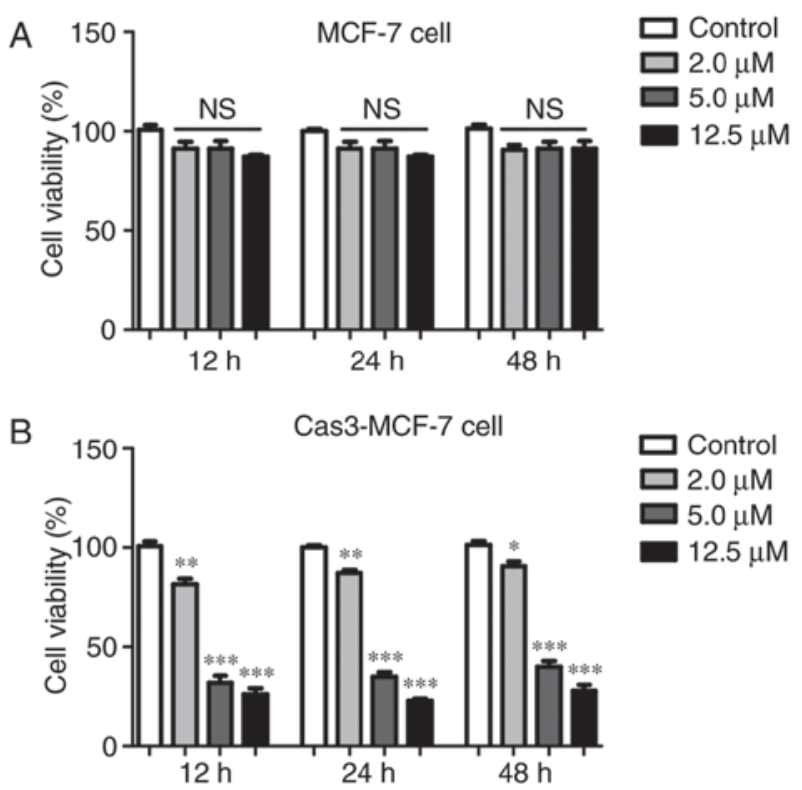

Figure 2. Rates of inhibition of MCF-7 cells and Cas3-MCF-7 cells following treatment with 0.0, 2.0,5.0 and 12.5 $\mu \mathrm{m} \mathrm{RA.} \mathrm{(A)} \mathrm{MCF-7} \mathrm{cells} \mathrm{and}$ (B) Cas3-MCF-7 cells were treated with varying doses of RA for 12, 24 and 48 h. Cell viability was determined by MTT assays. The experiments were repeated at least three times. The data are expressed as the mean \pm standard deviation of three experiments. ${ }^{*} \mathrm{P}<0.05,{ }^{* *} \mathrm{P}<0.01$ and ${ }^{* * * *} \mathrm{P}<0.001$ vs. control. Cas3, caspase-3; RA, rotundic acid.

between the different time points of 12,24 and $48 \mathrm{~h}$, which revealed similar inhibitory effects.

Annexin V-FITC and PI double-staining assay. To investigate whether RA also induced apoptosis in Cas3-MCF-7 cells, an annexin V-FITC and PI double-staining assay was performed. Cas3-MCF-7 cells were treated with RA at concentrations of 2.0, 5.0 and $12.5 \mu \mathrm{mol} / 1$ for 12,24 and $48 \mathrm{~h}$, and were then analyzed by flow cytometry. Fig. 3A indicates that, compared with that in the control group, the number of the early- and late-apoptotic cells increased significantly in the RA-treated groups. The inhibitory effects of RA on the Cas3-MCF-7 cells were dose-dependent within the range of 2-12.5 $\mu \mathrm{mol} / 1$. Treatment with RA at $12.5 \mu \mathrm{mol} / \mathrm{l}$ elicited the greatest apoptosis 
A

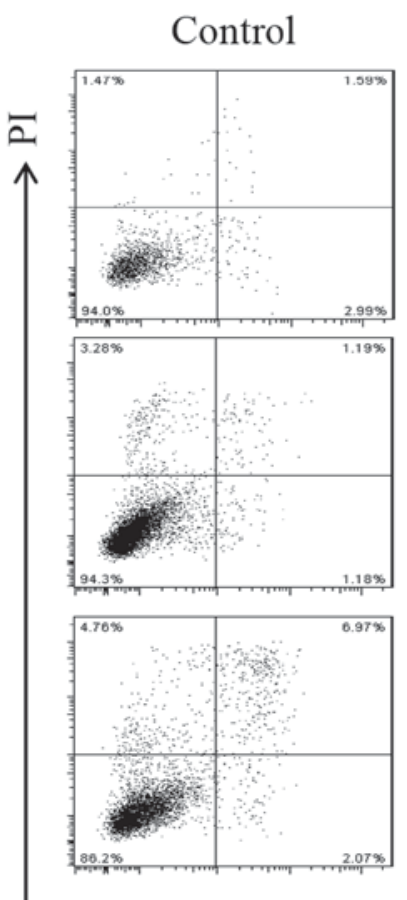

Rotundic acid $(\mu \mathrm{M})$
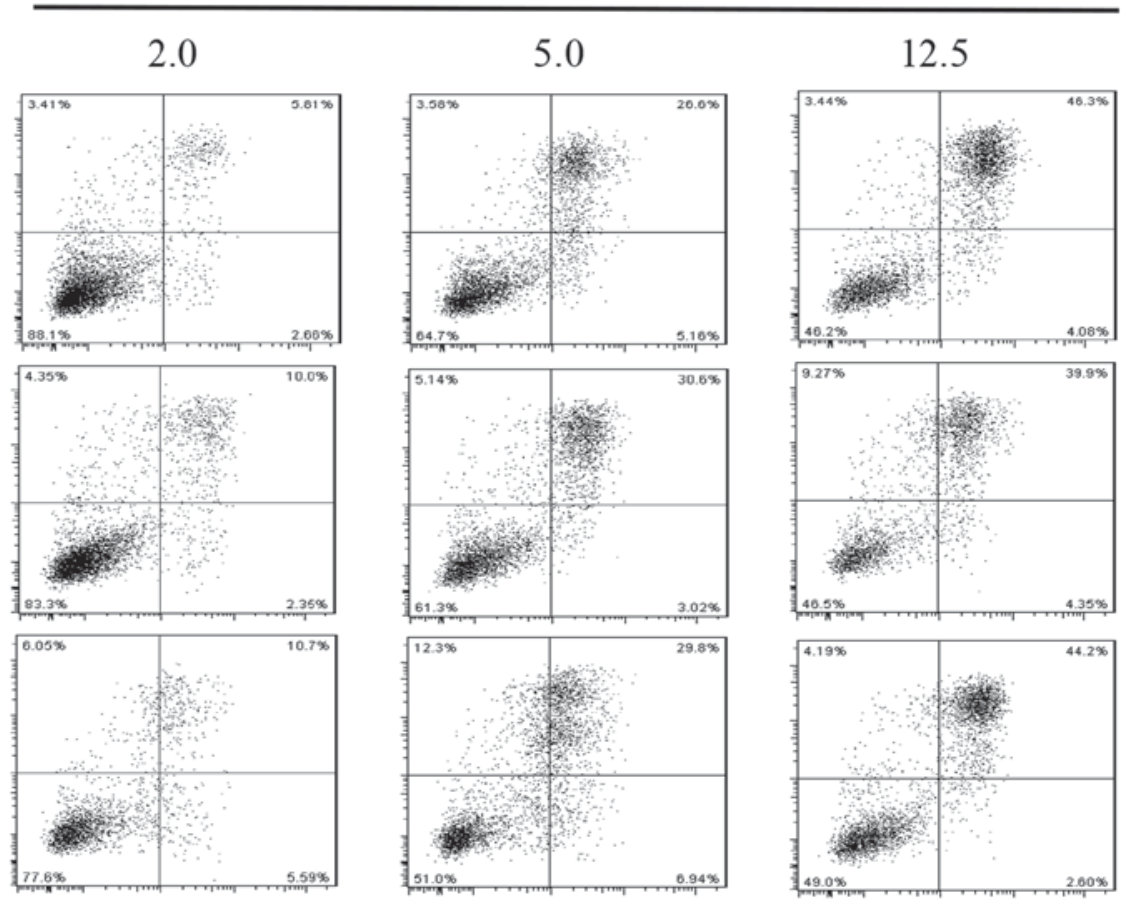

$12 \mathrm{~h}$

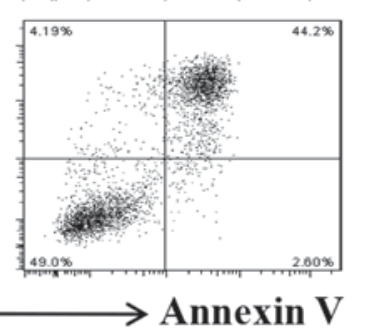

$48 h$

B

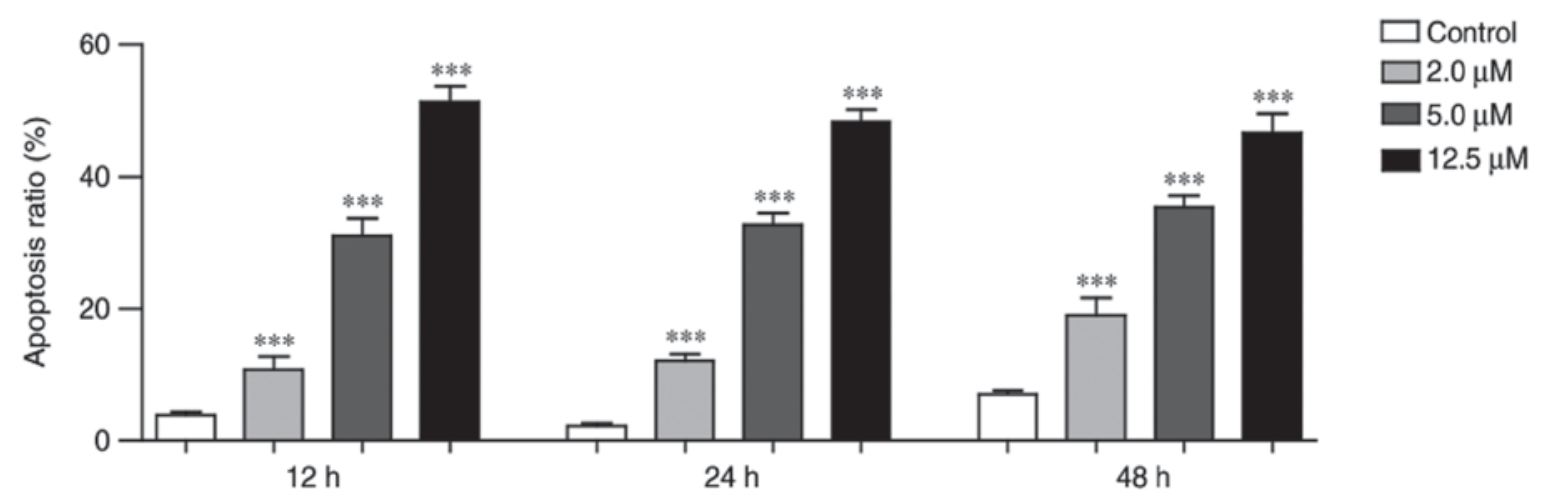

Figure 3. Detection of apoptosis by flow cytometry in Cas3-MCF-7 cells treated with RA. (A) Flow cytometric analysis of apoptosis in Cas3-MCF-7 cells treated with RA. The cells were exposed to either the control solution ( $0.1 \%$ dimethysulfoxide in medium) or RA at 2.0,5.0 and $12.5 \mu \mathrm{M}$, and incubated for 12 , 24 or $48 \mathrm{~h}$. (B) Proportions of apoptotic cells. The apoptotic cells were calculated as the proportions of apoptotic cells in the upper right portion and the lower right portion relative to the total number of the cells. Results are expressed as the mean \pm standard deviation of three experiments. ${ }^{* * * *} \mathrm{P}<0.001$ vs. control. Cas 3 , caspase-3; RA, rotundic acid; PI, propidium iodide.

capacity, which reached $52.8 \%$ at $12 \mathrm{~h}, 50.2 \%$ at $24 \mathrm{~h}$ and $49.6 \%$ at $48 \mathrm{~h}$ (Fig. 3B). Similar to the MTT assay results, there were no significant differences in the proportion of apoptotic cells between the different time points at 12 to $48 \mathrm{~h}$, which revealed a similar inhibitory effect at all three doses. These results indicate that RA significantly induced Cas3-MCF-7 cell apoptosis.

RA induces Cas3-MCF-7 cell apoptosis via the p53 signaling pathway. Cas3-MCF-7 cells were treated with RA at a concentration of 2-12.5 $\mu \mathrm{mol} / 1$ for 6,12 and $24 \mathrm{~h}$. p53, cleaved caspase- 3 and total caspase-3 levels were detected by western blotting, RT-qPCR or ELISA. As presented in Fig. 4A, the expression of p53 induced by RA in the Cas3-MCF-7 cells was dose-dependent within the range of 2-12.5 $\mu \mathrm{mol} / 1$ at 6,12 and $24 \mathrm{~h}$. However, only the expression of p53 at $24 \mathrm{~h}$ demonstrated the peak value. Quantification of p53 expression at
$12 \mathrm{~h}$ is presented in Fig. 4B. The RT-qPCR analysis confirmed that p53 gene expression was also induced by RA in a dose-dependent manner (Fig. 4C). The relative expression of the cleaved caspase-3/caspase-3 may reflect the molecular mechanism underlying apoptosis. The caspase-3 cell apoptosis signal that was activated by RA in the Cas3-MCF-7 cells also exhibited a dose-dependent effect within the range of 2-12.5 $\mu \mathrm{mol} / 1$ (Fig. 4D). The caspase-3 activity was also confirmed by ELISA (Fig. 4E). To further clarify the association between $\mathrm{p} 53$ and the caspase-3 activation in Cas3-MCF-7 cell apoptosis, RNA interference (RNAi) technology was applied to inhibit p53 expression in Cas3-MCF-7 cells. p53 expression in the Cas3-MCF-7 cells was significantly decreased following p53 gene silencing according to western blot analysis $(\mathrm{P}<0.001$; Fig. 5A and $\mathrm{B})$ and RT-qPCR $(\mathrm{P}<0.001$; Fig. 5C and D) analyses. When the p53 gene was silenced, RA 
A

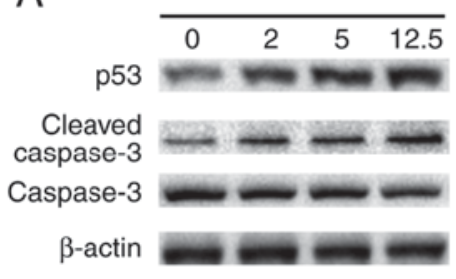

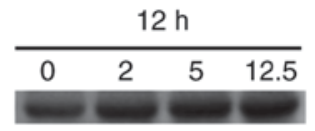

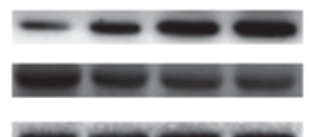

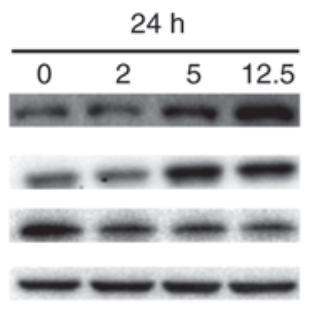

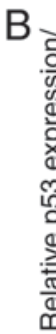
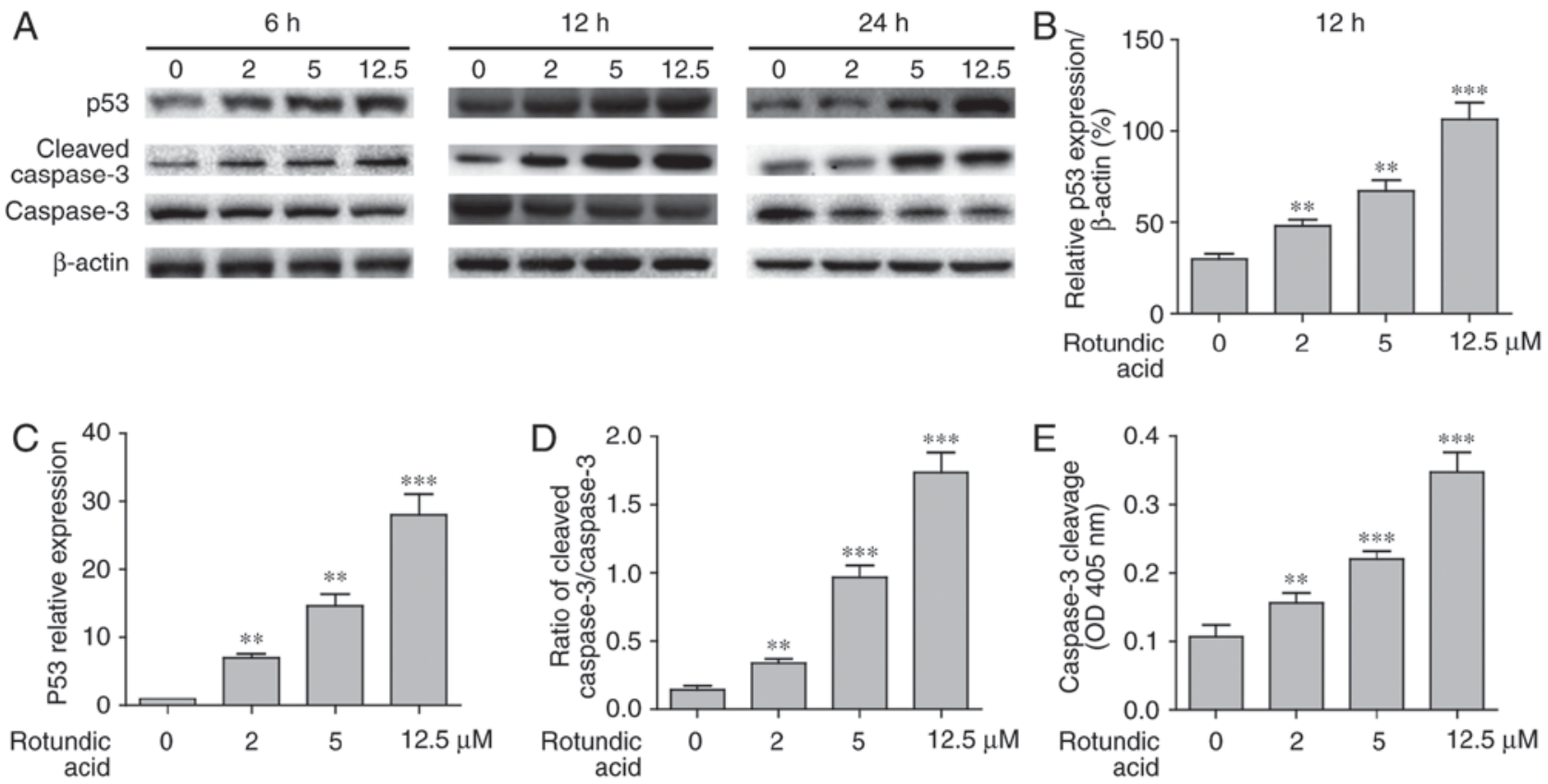

Figure 4. RA increases p53 expression and caspase-3 activity in Cas3-MCF-7 cells. (A) Cas3-MCF-7 cells were treated with various doses of RA for 6, 12 and $24 \mathrm{~h}$ prior to western blot analysis for the expression of caspase-3, cleaved caspase-3 and p53 protein in cells treated with $0.0,2.0,5.0$ and $12.5 \mu \mathrm{M}$ RA at 6 , 12 and $24 \mathrm{~h}$. (B) Quantification of p53 protein levels at the $12 \mathrm{~h}$ time point. (C) Relative gene expression of p53 at the $12 \mathrm{~h}$ time point. (D) Quantification of cleaved caspase-3 protein levels at the $12 \mathrm{~h}$ time point. (E) Caspase-3 activity detected by ELISA at the $12 \mathrm{~h}$ time point. The experiments were performed at least three times. Results are expressed as the mean \pm standard deviation. ${ }^{* *} \mathrm{P}<0.01$ and ${ }^{* * * *} \mathrm{P}<0.001$ vs. control. RA, rotundic acid; Cas3, caspase-3; OD, optical density.
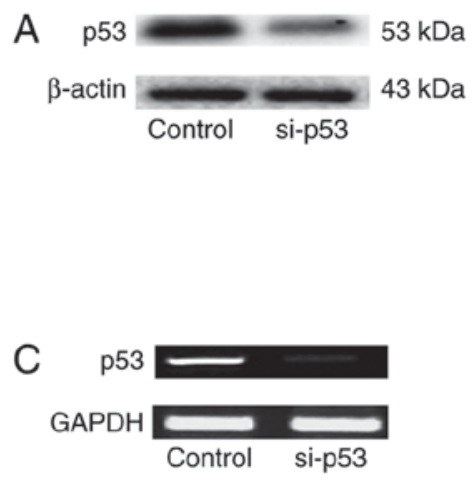
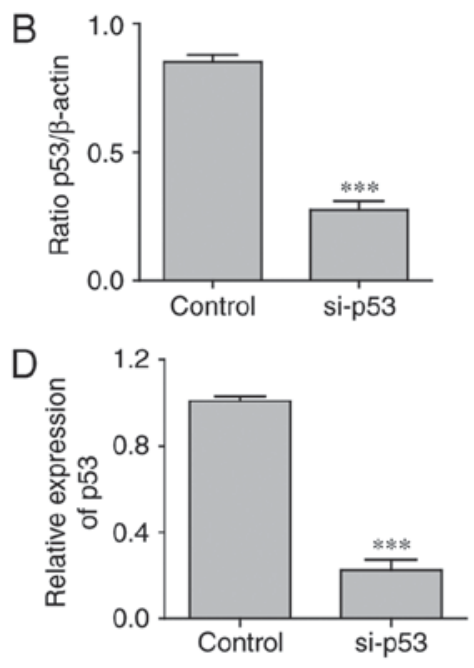
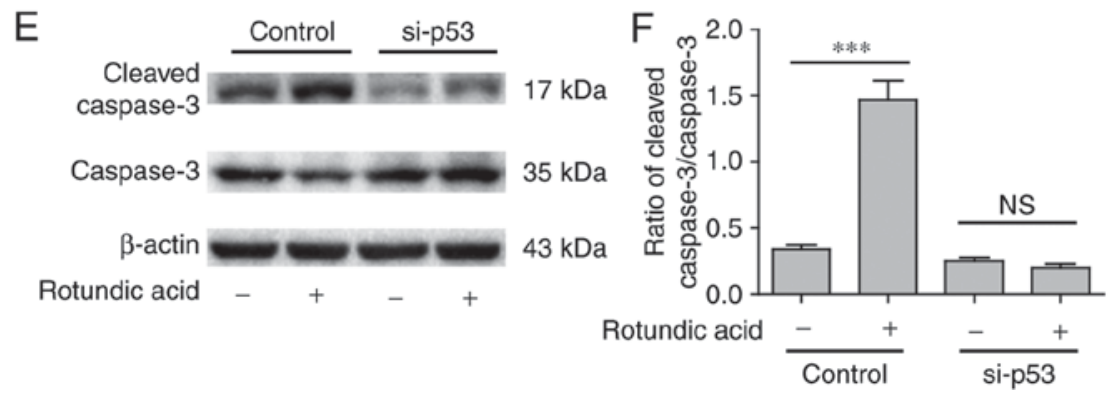

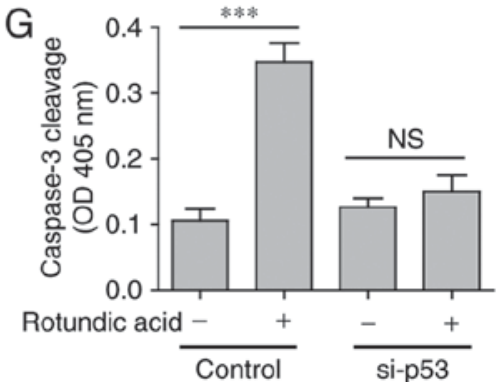

Figure 5. Silencing of p53 gene expression inhibits the caspase-3 activity induced by RA in Cas3-MCF-7 cells. Cas3-MCF-7 cells were transfected with p53 siRNA or non-target sequence siRNA (Scramble) kit for $24 \mathrm{~h}$. (A) Western blot analysis for the knockdown efficiency of p53. (B) Quantification of p53 protein levels $\left({ }^{* * * *} \mathrm{P}<0.001\right)$. (C) Reverse transcription-quantitative polymerase chain reaction analysis for the knockdown efficiency of p53. (D) Relative gene expression of $\mathrm{p} 53\left({ }^{* * *} \mathrm{P}<0.001\right)$. Detection of caspase-3 activity induced by RA following p53-siRNA treatment of Cas3-MCF-7 cells. (E) Western blot analysis for the expression of caspase-3. (F) Quantification of cleaved caspase-3 protein levels. (G) Caspase-3 activity detected by ELISA. Results are expressed as the mean \pm standard deviation of three experiments. ${ }^{* * *} \mathrm{P}<0.001$ vs. control. RA, rotundic acid; Cas3, caspase-3; si, small interfering; OD, optical density; NS, not significant. 
A

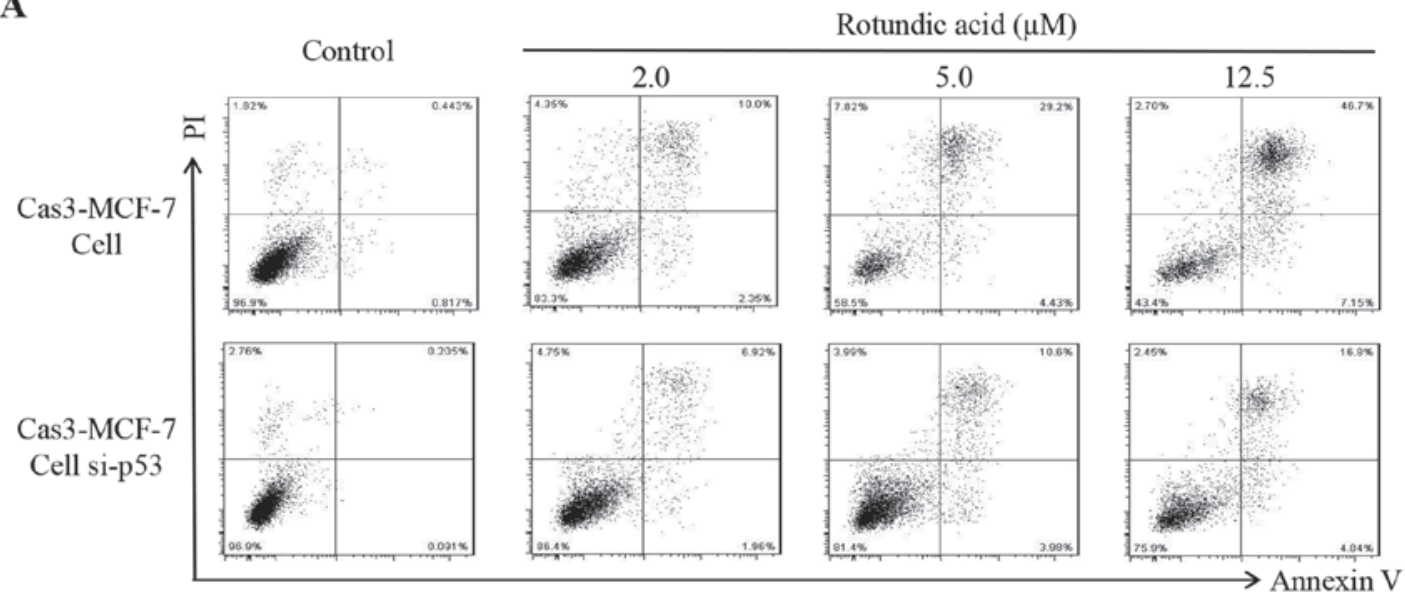

B

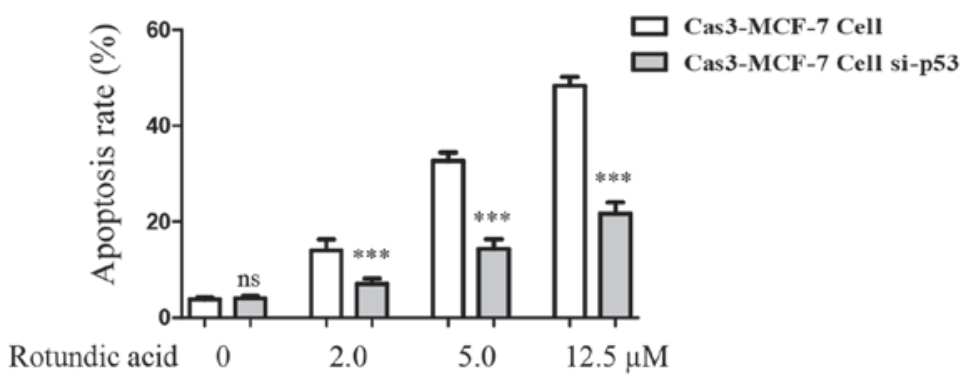

Figure 6. Detection of apoptosis by flow cytometry in p53-silenced Cas3-MCF-7 cells treated with RA. (A) Flow cytometric analysis of apoptosis in p53-silenced or non-silenced Cas3-MCF-7 cells treated with RA. The cells were exposed to RA at 0.0, 2.0, 5.0 and $12.5 \mu \mathrm{M}$ and incubated for $24 \mathrm{~h}$. (B) Proportions of apoptotic cells. Results are expressed as the mean \pm standard deviation of three experiments. ${ }^{* * *} \mathrm{P}<0.001$ vs. control. Cas3, caspase-3; RA, rotundic acid; NS, not significant; si, small interfering.

could not induce Cas3-MCF-7 cell caspase-3 activity ( $\mathrm{P}>0.05$; Fig. 5E-G), which was confirmed by western blotting and ELISA. These results indicate that RA induced Cas3-MCF-7 cell apoptosis via the p53 signaling pathway.

Silencing of $p 53$ decreases RA-induced Cas3-MCF-7 cell apoptosis. An annexin V-FITC and PI double-staining assay was also performed to investigate the outcome when the p53 gene was silenced in Cas3-MCF-7 cells following treatment with RA. The results demonstrated that the numbers of early- and late-apoptotic cells decreased significantly on the p53-silenced Cas3-MCF-7 cells comparing with untreated Cas3-MCF-7 cells when treated with RA at all three doses $(\mathrm{P}<0.001$; Fig. 6A and B). These results indicated that p53 serves an important function in RA-induced Cas3-MCF-7 cell apoptosis.

\section{Discussion}

Breast cancer is a common malignant cancer that has threatened the health of women worldwide over the last three decades (3). There are numerous factors that affect the biology of tumor cells during the occurrence and progression of breast cancer (24). Oncogenes have become increasingly important in the development of cancer. Caspase-3 deficiency may contribute to the chemotherapy-resistance of breast cancers. Reconstitution of caspase-3 sensitizes MCF-7 breast cancer cells to chemotherapy. Breast cancer metastasis and prognosis are associated with oncogene mutations and abnormal expression (25). p53 is an important tumor suppressor gene that resides in the majority of normal cells; however, it is often mutated in cancer cells $(26,27)$. Previous studies have demonstrated that p53 gene mutations are associated with the resistance of breast cancer $(28,29)$. Lee et al (15) also reported that RA demonstrated cytotoxicity, with an $\mathrm{IC}_{50}$ value of $9.5 \mu \mathrm{M}$ when applied to the MCF-7 cell lines; however, the precise mechanism has not been thoroughly studied and elucidated. The results of the present study are inconsistent with those of the study by Lee et al (15), as it was revealed that RA had limited function on the inhibition of the proliferation of MCF-7 cells treated with control plasmid, but the inhibitory effects of RA on the Cas3-MCF-7 cells were dose-dependent within the range of 2-12.5 $\mu \mathrm{mol} / \mathrm{l}$. This may be due to the transfection treatment of MCF-7 cells, or the different sources and the purity of the RA. However, this phenomenon indicates that caspase- 3 serves a critical function in rotundic acid-induced apoptosis, and suggests that caspase-3 deficiency may contribute to the chemotherapy resistance of breast cancer (30).

Although there are numerous studies pertaining to the extraction of RA in China, there have been few studies on its bioactivity due to a lack of interest from pharmacological researchers $(15,22)$. In our open patent, a considerable quantity of RA was isolated and purified from I. rotunda (31). As RA has the potential to be a native anticancer drug with sufficient sources, our research group has investigated and applied for a series of patents regarding RA and its derivatives over the last few years to investigate and use (32-36). The aim of the 
present study was to investigate the anticancer effect of RA on cell viability and apoptosis in the human breast cancer Cas3-MCF-7 cell line. RA was able to inhibit the viability of Cas3-MCF-7 cells at 2.0-12.5 $\mu \mathrm{M}$ between 12 and $48 \mathrm{~h}$. RA enhanced the apoptotic effector of caspase-3 activity and induced cell death. The RT-qPCR analysis and western blot assay confirmed that RA induced p53 gene and protein expression in a dose-dependent manner, which was consistent with caspase-3 activity. Caspase- 3 activation could be initiated by a number of upstream signal-regulated molecules (37-39). The increase in p53 gene expression induced cell apoptosis via caspase activity. In the present study, p53 was demonstrated to be increased in Cas3-MCF-7 cells treated with RA, indicating that RA induced p53 and caspase-3 activity in Cas3-MCF-7 cells, which then caused cell death.

To confirm the importance of the p53 pathway in the caspase-3 activation and RA-induced Cas3-MCF-7 cell apoptosis, RNAi technology was applied to inhibit p53 expression in MCF-7 cells. Subsequent to using a p53 siRNA kit to treat Cas3-MCF-7 cells for $24 \mathrm{~h}$, the expression levels of the p53 protein and gene were significantly decreased, which were then detected by western blot analysis and RT-qPCR assays. Flow cytometric analysis revealed that the numbers of early and late apoptotic cells decreased significantly compared with those of normal MCF-7 cells at 2.0, 5.0 and 15.5 $\mu \mathrm{M}$ RA. On the basis of these results, it was concluded that RA exerted antitumor functions by inducing p53/caspase-3 activation in target cells. In summary, the results of the present study identified that RA functioned to inhibit Cas3-MCF-7 cell viability by inducing apoptosis. To the best of our knowledge, the present study is the first to reveal the exact mechanism of RA in the induction of Cas3-MCF-7 cell apoptosis. Caspase-3 serves an important function in the execution of apoptotic. Caspase-3 deficiency or downregulation has been reported in breast and other types of cancer. Although caspase-3 is deficient in MCF-7 cells, it has been demonstrated that caspase- 3 reconstitution significantly enhanced radiation-induced apoptosis, with a decrease in the survival fraction, an increase in caspase activation, cleavage of cellular death substrates and mitochondrial depolarization (40). Caspase-3 reconstitution may be used as a gene targeting therapy combined with chemotherapy or radiotherapy for the treatment of caspase-3-deficient cancer. Collectively, the results of the present study indicate that caspase- 3 serves a critical function in RA-induced apoptosis, and suggest that caspase-3 deficiency may contribute to the chemotherapy-resistance of breast cancers. Reconstitution of caspase-3 sensitizes MCF-7 breast cancer cells to chemotherapy. RA has the potential for development as a new drug in combination with gene therapy for the treatment of human breast cancer with caspase- 3 deficiency.

\section{Acknowledgements}

Not applicable.

\section{Funding}

The present study was supported in part by the Jilin Provincial Natural Science Foundation of China (grant nos. 20140520014JH and 20180101135JC), the Interdisciplinary Chemistry and Medicine Foundation of Jilin University (grant no. JDYYJCHX004) and the National Natural Science Foundation of China (grant no. 31470418).

\section{Availability of data and materials}

All data generated or analyzed during the present study are included in this published article.

\section{Authors' contributions}

MN, XW and HL planned and performed the experiments, analyzed data and wrote the manuscript. DY, WS and HX performed the experiments. YH and QZ designed, interpreted and funded the study, and wrote the manuscript.

\section{Ethics approval and consent to participate}

Not applicable.

\section{Patient consent for publication}

Not applicable.

\section{Competing interests}

The authors declare that they have no competing interests.

\section{References}

1. Metzger-Filho O, de Azambuja E, Bradbury I, Saini KS, Bines J, Simon SD, Dooren VV, Aktan G, Pritchard KI, Wolff AC, et al: Analysis of regional timelines to set up a global phase III clinical trial in breast cancer: The adjuvant lapatinib and/or trastuzumab treatment optimization experience. Oncologist 18: 134-140, 2013.

2. Bower JE, Greendale G, Crosswell AD, Garet D, Sternlieb B, Ganz PA, Irwin MR, Olmstead R, Arevalo J and Cole SW: Yoga reducesinflammatory signalinginfatigued breastcancersurvivors: A randomized controlled trial. Psychoneuroendocrinology 43: 20-29, 2014

3. Pu Z, Zhang X, Chen Q, Yuan X and Xie H: Establishment of an expression platform of OATP1B1 388GG and 521CC genetic polymorphism and the therapeutic effect of tamoxifen in MCF-7 cells. Oncol Rep 33: 2420-2428, 2015.

4. Hu D, Su C, Jiang M, Shen Y, Shi A, Zhao F, Chen R, Shen Z, Bao J and Tang W: Fenofibrate inhibited pancreatic cancer cells proliferation via activation of $\mathrm{p} 53$ mediated by upregulation of LncRNA MEG3. Biochem Biophys Res Commun 471: 290-295, 2016.

5. Bertheau P, Lehmann-Che J, Varna M, Dumay A, Poirot B, Porcher R, Turpin E, Plassa LF, de Roquancourt A, Bourstyn E, et al: p53 in breast cancer subtypes and new insights into response to chemotherapy. Breast 2 (Suppl 22): S27-S29, 2013.

6. Sana M and Malik HJ: Current and emerging breast cancer biomarkers. J Cancer Res Ther 11: 508-513, 2015.

7. Shah U, Shah R, Acharya S and Acharya N: Novel anticancer agents from plant sources. Chin J Nat Med 11: 16-23, 2013 (In Chinese),

8. Khan F, Ahmed F, Pushparaj PN, Abuzenadah A, Kumosani T, Barbour E, AlQahtani M and Gauthaman K: Ajwa date (Phoenix dactylifera L.) extract inhibits human breast adenocarcinoma (MCF7) cells in vitro by inducing apoptosis and cell cycle arrest. PLoS One 11: e0158963, 2016.

9. Gerber DE: Targeted therapies: A new generation of cancer treatments. Am Fam Physician 77: 311-319, 2008.

10. He YF, Nan ML, Zhao YW, Sun WY, Li W and Zhao QC: Design, synthesis and evaluation of antitumor activity of new rotundic acid acylhydrazone derivatives. Z Naturforsch C 71: 95-103, 2016.

11. Haraguchi H, Kataoka S, Okamoto S, Hanafi M and Shibata K: Antimicrobial triterpenes from Ilex integraand the mechanism of antifungal action. Phytother Res 13: 151-156, 1999. 
12. Zhao WM, Wolfender JL, Hostettmann K, Cheng KF, Xu RS and Qin GW: Triterpenes and triterpenoid saponins from mussaenda pubescens. Phytochemistry 45: 1073-1078, 1997.

13. Bhattacharyya $\mathbf{J}$ and Almeida MD: Isolation of the constituents of the root-bark of guettarda platypoda. J Nat Prod 48: 148, 1985

14. Saimaru H, Orihara Y, Tahsakul P, Kang YH, Shibuya M and Ebizuka Y: Production of triterpene acids by cell suspension cultures of Olea europaea. Chem Pharm Bull (Tokyo) 55 784-788, 2007.

15. Lee TH, Juang SH, Hsu FL and Wu CY: Triterpene acids from the leaves of planchonella duclitan (Blanco) bakhuizan. J Chin Chem Soc 52: 1275-1280, 2005.

16. Fulda S: Inhibitor of apoptosis (IAP) proteins as therapeutic targets for radiosensitization of human cancers. Cancer Treat Rev 38: 760-766, 2012.

17. Yin J, Wang F, Kong Y, Wu R, Zhang G, Wang N, Wang L, Lu Z and Liang M: Antithrombin III prevents progression of chronic kidney disease following experimental ischaemic-reperfusion injury. J Cell Mol Med 21: 3506-3514, 2017.

18. Lu Z, Cheng D, Yin J, Wu R, Zhang G, Zhao Q, Wang N, Wang F and Liang M: Antithrombin III protects against contrast-induced nephropathy. EBioMedicine 17: 101-107, 2017.

19. Hengartner MO: The biochemistry of apoptosis. Nature 407: 770-776, 2000

20. Antony ML, Kim SH and Singh SV: Critical role of p53 upregulated modulator of apoptosis in benzyl isothiocyanate-induced apoptotic cell death. PLoS One 7: e32267, 2012.

21. Xu R: Studies on the chemical components and antitumor activity of ilex rotunda thunb. Ph.D. Thesis, Guangzhou University of Chinese Medicine, 2009 (In Chinese).

22. He YF, Nan ML, Sun JM, Meng ZJ, Yue FG, Zhao QC, Yang XH and Wang H: Synthesis, characterization and cytotoxicity of new rotundic acid derivatives. Molecules 17: 1278-1291, 2012.

23. Livak KJ and Schmittgen TD: Analysis of relative gene expression data using real-time quantitative PCR and the 2(-Delta Delta C(T)) method. Methods 25: 402-408, 2001.

24. Mrózek E, Layman R, Ramaswamy B, Lustberg M, Vecchione A, Knopp MV and Shapiro CL: Phase II trial of neoadjuvant weekly nanoparticle albumin-bound paclitaxel, carboplatin, and biweekly bevacizumab therapy in women with clinical stage II or III HER2-negative breast cancer. Clin Breast Cancer 14: 228-234, 2014.

25. Zuo S, Liu C, Wang J, Wang F, Xu W, Cui S, Yuan L, Chen X, Fan W, Cui M and Song G: IGFBP-rP1 induces p21 expression through a p53-independent pathway, leading to cellular senescence of MCF-7 breast cancer cells. J Cancer Res Clin Oncol 138 1045-1055, 2012

26. Steigerwald C, Rasenberger B, Christmann M and Tomicic MT: Sensitization of colorectal cancer cells to irinotecan by the survivin inhibitor LLP3 depends on XAF1 proficiency in the context of mutated p53. Arch Toxicol 92: 2645-2648, 2018.
27. Meng X, Bi J, Li Y, Yang S, Zhang Y, Li M, Liu H, Li Y, Mcdonald ME, Thiel KW, et al: AZD1775 increases sensitivity to olaparib and gemcitabine in cancer cells with p53 mutations. Cancers (Basel) 10: E149, 2018.

28. Shokouh TZ, Ezatollah A and Barand P: Interrelationships Between Ki67, HER2/neu, p53, ER, and PR status and their associations with tumor grade and lymph node involvement in breast carcinoma subtypes: Retrospective-observational analytical study. Medicine (Baltimore) 94: e1359, 2015.

29. Verma $S$ and Rao BJ: $p 53$ suppresses BRCA2-stimulated ATPase and strand exchange functions of human RAD51. J Biochem 154: 237-248, 2013.

30. Wesierska-Gadek J, Hackl S, Zulehner N, Maurer M and Komina O: Reconstitution of human MCF-7 breast cancer cells with caspase- 3 does not sensitize them to action of CDK inhibitors. J Cell Biochem 112: 273-288, 2011.

31. Zhao QC, Nan ML, He YF and Chen SW: Application of rotundic acid in the cardiovascular disease prevention. Chn 201010204596.9, 2010 (In Chinese).

32. Zhao QC, Nan ML, He YF and Chen SW: Application of rotundic acid in the preparation of lipid-lowering drugs. $\mathrm{CHN}$ 201010204607. 3, 2010 (In Chinese).

33. He YF, Zhao QC, Nan ML, Wang HL, Ma JS, Zhao YW, et al: Application of rotundic acid and its derivatives in the preparation of anticancer drugs. CHN 201010607515. x, 2010 (In Chinese).

34. Nan ML, Zhao QC, He YF, Chen SW, Zhao YW and Wang LP: Pharmaceutical compositions from ilex rotunda thunb. and Its Application. CHN 201010607550. 1, 2010 (In Chinese).

35. Zhao QC, He YF, Nan ML, Chen SW, Zhao YW and Wang LP Synthesis method of rotundic acid derivatives and their application in the preparation of cardiovascular disease prevention drugs. CHN 20110030007. 4, 2011 (In Chinese).

36. He YF, Nan ML, Zhao QC, Zhao YW and Yue FG: Application of amino acid modified rotundic acid derivatives in the preparation of anticancer drugs. CHN 201110351365.5, 2011 (In Chinese).

37. Zhang M, Yan H, Li S and Yang J: Rosmarinic acid protects rat hippocampal neurons from cerebral ischemia/reperfusion injury via the Akt/JNK3/caspase-3 signaling pathway. Brain Res 1657: 9-15, 2017.

38. Venkatesan RS and Sadiq AM: Effect of morin-5'-sulfonic acid sodium salt on the expression of apoptosis related proteins caspase 3 , Bax and $\mathrm{Bcl} 2$ due to the mercury induced oxidative stress in albino rats. Biomed Pharmacother 85: 202-208, 2017.

39. Mondal A and Bennett LL: Resveratrol enhances the efficacy of sorafenib mediated apoptosis in human breast cancer MCF7 cells through ROS, cell cycle inhibition, caspase 3 and PARP cleavage. Biomed Pharmacother 84: 1906-1914, 2016.

40. Yang XH, Edgerton S and Thor AD: Reconstitution of caspase-3 sensitizes MCF-7 breast cancer cells to radiation therapy. Int J Oncol 26: 1675-1680, 2005. 